\title{
Responsabilidade social universitária: uma definição prudente e responsável
}

François Vallaeys ${ }^{1}$

\begin{abstract}
Resumo
O artigo propõe uma definição da responsabilidade social universitária (RSU) fundamentada em uma análise filosófica dos desafios éticos complexos enfrentados pela humanidade na era do seu perigo de insustentabilidade. Critica as limitações de uma visão gerencial estreita da responsabilidade social tal como as ferramentas de gestão empresarial abordam e aprofunda a definição de responsabilidade social universitária baseada em quatro grandes impactos da instituição do ensino superior: impactos organizacionais, educativos, cognitivos e de participação social. Essa visão transversal da responsabilidade social universitária permite redefinir profundamente o papel das ciências na globalização e lutar contra a mercantilização do ensino superior.
\end{abstract}

Palavras-chave: ética da sustentabilidade; pensamento complexo; desenvolvimento sustentável; responsabilidade social universitária; gestão do conhecimento.

\section{Abstract}

The article proposes a definition of the university social responsibility (USR) based on a philosophical analysis of complex ethical challenges that deals with the humanity and its dangerous unsustainability. It criticizes the limits of a managerial tiny point of view about social responsibility just as the tools of business management focus it, and deepens the university social responsibility definition based on 4 greats impacts of universities: organizational, educational, cognitive, and social participation. This transversal vision of university social responsibility allows the deep redefinition of science role in globalization and the fight against commercialization of education.

Keywords: ethics of sustainability, complex thinking, sustainable development, university social responsibility, knowledge management.

\section{Teoria da responsabilidade social: virtude, justiça, sustentabilidade para uma ética em “3D”}

A responsabilidade social é uma nova responsabilidade central que complementa as responsabilidades moral e jurídica, sendo uma responsabilidade coletiva promotora de criatividade política em vez de uma responsabilidade que rffeffresponsabilize pessoalmente (Vallaeys, 2011).

As responsabilidades moral e jurídica regulam os nossos atos, enquanto a responsabilidade social regula os nossos impactos, isto é, não o que fazemos com as suas consequências imediatas e locais, mas o que produz o que fazemos com as suas emergências sistémicas afastadas e globais. Uma vez que entendemos que a responsabilidade social é uma responsabilidade pelos impactos e que os impactos não são atos, podemos abordar, em toda a riqueza teórica e prática, o que significa a responsabilidade social das organizações e, em particular, das universidades.

Os problemas que exigem uma socialização da responsabilidade dizem respeito sempre a questões sistémicas que decorrem das rotinas sociais de uma multitude de pessoas que convivem, impactos muitas vezes invisíveis sem o concurso da investigação científica (as alterações climáticas por exemplo). Estas rotinas, ligadas a um modo de viver, produzem efeitos

\footnotetext{
${ }^{1}$ Doutor em Filosofia. Professor-Investigador na Escuela de Postgrado de la Universidad del Pacífico (Lima, Perú). Presidente da Unión de Responsabilidade Social Universitária (RSU) Latinoamericana (URSULA). f.vallaeys@up.edu.pe. ORCID: https://orcid.org/0000-0003-2879-1695
} 
colaterais crónicos não desejados que ferem a vida social e precisam, por isso, de uma corresponsabilização por parte dos cidadãos associados para (1) perceberem que o seu modo de viver gera problemas endémicos que não são sustentáveis e (2) instituir as mudanças sociais necessárias para resolver os referidos problemas. A passagem do simples padecer individual dos problemas sociais sem tomada de consciência da corresponsabilidade ativa para a solução consensual dos problemas comuns é o que o filósofo Dewey designava por constituição de um Público (Dewey, 1927), quer dizer, o surgimento de um sujeito coletivo político capaz de colocar o seu próprio destino nas suas mãos e inovar para se dotar da constituição política adequada, justa e sustentável, com bons órgãos de regulação da ação coletiva. A responsabilidade social é uma responsabilidade política por excelência, isto é, relacional, não a responsabilidade individual dos representantes eleitos, senão a de todos os cidadãos unidos.

Hoje é óbvio que os nossos problemas coletivos estão ligados (1) ao perigo da inabitabilidade ecológica do planeta devido ao produtivismo industrial e (2) à carência de controlo dos sistemas sociais modernos (sistemas económico, financeiro, científico e técnico sobretudo) que se desenvolvem de forma acelerada, desenfreada e autónoma sem que possamos garantir que continuam a ter uma desejabilidade social norteada por poderes legítimos. O problema ecológico global é uma consequência do problema de controlo político global. Nos inícios da Modernidade era necessário decidir como controlar politicamente o domínio político e como sair do estado de escassez coletiva. Inventámos a Democracia e a Tecnociência industrial para resolver ambos os problemas com sucesso. Hoje, o maior problema é o de recuperar um poder democrático sobre as potencialidades derivadas da Tecnociência nas mãos do interesse lucrativo cego e da "inteligência cega" (Morin, 2004) dos científicos especializados de todo o tipo, que sem querer caminham no sentido da validação da lei de Gabor: "Tudo o que se puder fazer far-se-á, independentemente das consequências". Ter o poder de controlo sobre o seu próprio poder, para que não se lhe escape como força incontrolável, esse é o dever do ser responsável. O risco político de outrora era o da superabundância de poder político. O risco político de hoje é o de uma carência de poder político, uma impossibilidade de governar as potências sociais desencadeadas pela Modernidade industrial. Por isso a nossa época é a época da responsabilidade e da reflexividade, a do domínio do domínio (Serres, 1990), a do "princípio responsabilidade" (Jonas, 1979). Mas é uma responsabilidade rara e difícil de assumir: uma responsabilidade coletiva, mutualizada, partilhada, e não uma responsabilidade individual de cada sujeito (pessoa ou organização), é uma responsabilidade "social", meta-subjetiva.

Distinguir bem as três responsabilidades fundamentais (moral, jurídica, social) é, pois, uma tarefa filosófica muito importante de forma a evitar confusões no momento de analisar o que é a responsabilidade social corporativa (CSR) ou a responsabilidade social universitária (RSU) e, sobretudo, para não as continuarmos a confundir com a ação filantrópica para terminar por cair no greenwashing. De acordo com Morin (2004) e Vallaeys (2011), a ética complexa que devemos assumir visualiza-se em três dimensões, é uma "ética em 3D" (Quadro 1). 
Quadro 1 - As três dimensões da ética complexa

\begin{tabular}{|c|c|c|c|}
\hline Ética em “3D” & $\begin{array}{l}\text { 1a dimensão: } \\
\text { Auto-ética }\end{array}$ & $\begin{array}{l}\text { 2a dimensão: } \\
\text { Socio-ética }\end{array}$ & $\begin{array}{l}\text { 3a dimensão: } \\
\text { Antropo-ética }\end{array}$ \\
\hline Tipo de deveres & Virtude & Justiça & Sustentabilidade \\
\hline Sujeito do dever & $\begin{array}{l}\text { A pessoa (deveres } \\
\text { pessoais) }\end{array}$ & $\begin{array}{c}\text { A comunidade } \\
\text { (deveres interpessoais) }\end{array}$ & $\begin{array}{c}\text { A Humanidade (deveres } \\
\text { transgeracionais) }\end{array}$ \\
\hline Objeto do dever & Os atos & As leis & O mundo \\
\hline Âmbito da obrigação & A consciência pessoal & O Estado de direito & $\begin{array}{l}\text { A governança } \\
\text { internacional }\end{array}$ \\
\hline $\begin{array}{l}\text { Tipo de } \\
\text { responsabilidade }\end{array}$ & Responsabilidade moral & $\begin{array}{c}\text { Responsabilidade } \\
\text { jurídica }\end{array}$ & Responsabilidade social \\
\hline $\begin{array}{l}\text { Gerador de } \\
\text { responsabilidade }\end{array}$ & $\begin{array}{l}\text { O mal próprio e a dor } \\
\text { alheia }\end{array}$ & $\begin{array}{l}\text { O ato ilegal e a } \\
\text { injustiça }\end{array}$ & $\begin{array}{l}\text { O impacto negativo e a } \\
\text { insustentabilidade } \\
\text { sistémica }\end{array}$ \\
\hline Modo de regulação & A moral & O direito & A política \\
\hline
\end{tabular}

Fonte: Morin (2004) e Vallaeys (2011).

Nesta ética complexa, é importante destacar três aspectos:

1 - Nenhuma dimensão pode funcionar de forma separada das demais sem decair em patologia ética (fanatismo moral, dogmatismo jurídico, totalitarismo ecológico).

2 - A "Sustentabilidade" não deve reduzir-se aos assuntos ecológicos (proteção da "Natureza") devendo ser entendida de forma complexa como o cuidado pela continuidade da liberdade da humanidade, como justiça entre as gerações humanas, com respeito pela autonomia e dignidade das gerações seguintes e com respeito pelos esforços éticos das gerações anteriores.

3 - A "governança" começa quando já não é possível o "governo", isto é, quando os atores devem regular juntos a sua ação coletiva sem que um possa dar ordens aos demais (sem que um governe os demais). Uma situação de governo implica uma cadeia hierárquica de ordens aceites e sanções seguras em caso de desobediência (Luhmann, 1975). Uma situação de governança implica a necessidade de regular-se mutuamente com vista a um bem comum (a habitabilidade planetária, o equilíbrio financeiro mundial, a superação do dumping social e fiscal internacional, etc.) na ausência de um governo que coaja todos os atores debaixo de uma mesma lei.

A governança produz acordos de corresponsabilidade sob normas vigiadas mutuamente entre pares. A maioria dos nossos impactos negativos atuais apela à construção de regulações por governança, dado que implicam a coordenação transnacional e meta-governamental de múltiplos atores que não podem satisfazer-se nem com as autorregulações do mercado, nem com as leis de cada Estado por seu lado (Ostrom, 1990). Os ideólogos liberais recusam a governança porque entendem que o mercado é suficiente para regular a ação coletiva. Os ideólogos socialistas também recusam a governança porque entendem que nunca será eficaz e que são necessárias leis para coagir os agentes sociais. Nem os liberais nem os socialistas entendem do que trata a responsabilidade social, por isso os primeiros reduzem-na a filantropia corporativa (a responsabilidade moral do bom CEO virtuoso) e os segundos negam- 
na em nome da responsabilidade jurídica (a obrigação estatal). Na realidade, uma regulação socialmente responsável necessita tanto da lei como do mercado, mas não se limita a ambos, é uma regulação híbrida que implica também associações e inovações sociais entre pares, para além do laissez-faire liberal e da coação legal. Pensar uma verdadeira responsabilidade social liberta-nos do conflito sempre eterno entre liberais e socialistas e apresenta-nos o desafio de instituir uma verdadeira corresponsabilidade para o destino da humanidade, presente e futura, usando todas as possibilidades de regulação da ação coletiva (Quadro 2).

Quadro 2 - Possibilidades de regulação da ação coletiva

\begin{tabular}{|l|c|c|c|}
\hline Ética & $\begin{array}{c}\text { Autorregulação não programada: } \\
\text { Compromisso pessoal }\end{array}$ & Eu obrigo-me & A minha lei \\
\hline Mercado & $\begin{array}{c}\text { Heterorregulação não programada: } \\
\text { Feedbacks sistémicos }\end{array}$ & Ele obriga-nos & Sem lei \\
\hline Direito & $\begin{array}{c}\text { Heterorregulação programada: } \\
\text { Coação jurídica }\end{array}$ & A lei obriga-nos & $\begin{array}{c}\text { Lei dura } \\
\text { (hard) }\end{array}$ \\
\hline Associação (partnership) & $\begin{array}{c}\text { Autorregulação programada: } \\
\text { Obrigação mútua }\end{array}$ & Nós obrigamo-nos & Lei leve (soft) \\
\hline
\end{tabular}

Fonte: Fonte: Vallaeys (2011).

\section{As normas de responsabilidade social organizacionais serão suficientes para suprimir os impactos negativos?}

A nossa reconstrução filosófica de uma definição de responsabilidade social em termos de corresponsabilidade pelos impactos sociais e ambientais negativos que decorrem sistemicamente do modo de viver coletivo não é uma invenção ad hoc correspondendo antes ao consenso efetivo que se vai gerando internacionalmente em torno da noção e que a Norma ISO 26000 de responsabilidade social (2010) expressa nitidamente: a responsabilidade social de uma organização é a sua responsabilidade pelos impactos dos quais participa no seu contexto social quer local quer global. Mas, como os impactos não são atos, ninguém pode assumir esta responsabilidade sozinho sem se associar com os demais atores do campo social. Esta dimensão intrinsecamente coletiva da responsabilidade social todavia não está muito bem percebida.

O que está a nascer é a sensibilidade ética relativa aos contornos das ligações entre atos individuais e impactos globais. O auge na agenda pública internacional dos temas da insustentabilidade ambiental e injustiças da globalização económica habitua-nos cada vez mais à perceção das "pegadas" ecológicas e sociais que acompanham os nossos atos quotidianos de compra, transporte, consumo, produção, etc. Alfabetizamo-nos na preocupação ética pelo distante: A minha compra não manterá um sistema injusto de exploração de trabalhadores sem direitos? $\mathrm{O}$ meu transporte não aumentará as emissões de $\mathrm{CO}_{2}$ na atmosfera? $\mathrm{O}$ meu trabalho não promoverá a colisão das ciências com os interesses privados das multinacionais? Por tudo isto começamos a exigir cada vez mais uma gestão socialmente responsável às empresas, organizações, instituições com as quais nos vinculamos. 
Assim, nas últimas décadas, foram desenvolvidos numerosos standards de boas práticas empresariais (ISO 14000, EMAS, SD 21000, AA 1000, SA 8000, SGE 21, GLOBAL, GAP, GRI, Dow Jones Sustainability Index, ISO 26000, etc.). Estas normas definem boas práticas de gestão que cada organização deveria seguir, de acordo com o seu próprio core business, independentemente das leis às quais está submetida em cada Estado em que opera. Estas normas são de aceitação voluntária (dado que não são leis), mas espera-se que da pressão conjunta dos clientes, investidores, governos, profissionais, dirigentes, entre outros, se tornem universais. São definidas muitas vezes por especialistas, por vezes em mesas redondas de multi stakeholders ou, inclusivamente, através de longas negociações entre atores sociais privados e públicos, nacionais e internacionais, como foi o caso da norma ISO 26000 (Capron et al., 2011). Pretendem que a sua legitimidade decorra tanto da sua pertinência ética (definição de boas ações universalizáveis) como da sua eficácia técnica (definição de qualidade avaliável e bem sucedida). Pretendem também complementar como soft law as irremediáveis carências da hard law dos Estados limitados a legislar sobre o seu próprio território quando os problemas ocorrem agora a nível global. Contudo, não existe dúvida de que a soft law não deve substituir nunca a hard law, que antes complementa e antecipa.

As universidades estão atualmente a entrar nesta dinâmica dos standards de boas práticas normalizadas e começam a formular, para além das iniciativas socialmente responsáveis de cada uma, ferramentas de gestão que pretendem servir de modelo e paradigma para qualquer universidade: STARS na União Europeia, LIFE no Reino Unido, AISHE na Holanda, PLAN VERT em França, Memorias de Sostenibilidad y Responsabilidad Social em Espanha ... As Nações Unidas também promovem o tema através da UNAI (United Nations Academic Impact, 2010) e as Escolas de Negócios subscrevem os PRME (Principles for Responsible Management Education). Na América Latina também promovemos, desde os primeiros anos do novo século, uma RSU que deu lugar à publicação de um Manual de primeros pasos en responsabilidad social universitaria (Vallaeys et al., 2009).

Tal significa que tudo está bem e que é necessário confiar neste movimento voluntário das organizações que aceitam cada vez mais as normas de gestão socialmente responsável para um mundo mais justo e sustentável? Na realidade, se analisarmos com maior profundidade estas normas e as organizações que as adotam, percebemos que não fazem mais do que definir algumas "boas práticas" que cada organização implementa de forma solitária, no "seu" processo de gestão, com os "seus" colaboradores e as "suas" partes interessadas. Isto, sem dúvida, permite a promoção de comportamentos mais virtuosos no seio das organizações (boas práticas ambientais, igualdade de género nos cargos dirigentes, melhor relação laboral com os empregados, participação em atos de solidariedade com populações vulneráveis...) motivo pelo qual podemos certamente falar de maior responsabilidade moral das organizações que se preocupam com a RSO. Mas falta muito para que dita responsabilidade moral se torne responsabilidade social provocando mudanças em todo o campo social, entre as organizações (e já não no seu seio) e por cima de todas as organizações.

As atuais normas de responsabilidade social não animam, para lá das boas práticas, movimentos de associação em corresponsabilidade inter e transorganizacional que possam realmente romper com as tendências injustas e insustentáveis do sistema atual e traduzir-se 
em inovações sociais capazes de suprimir os impactos negativos crónicos da "sociedade mundial do risco" (Beck, 1986). Por exemplo, defendem a redução da pegada ecológica de cada empresa por si só, mas não defendem a implementação de um sistema económico novo como é o da "economia circular" ou da "economia de funcionalidade" que implicam uma gestão inter e trans organizacional. Contudo, como esperar uma redução da pegada ecológica global se continuamos com um sistema económico baseado no incremento das vendas e na obsolescência programada?

O erro filosófico das normas de responsabilidade social é o de confundir os atos das organizações com os impactos sistémicos que provocam. Tal confusão condena, de antemão ao fracasso, qualquer esforço na intenção de atacar as causas profundas que conduzem aos impactos negativos sistémicos, pois a sustentabilidade do mundo não se reorganiza se pedirmos apenas a alguns atores que se portem bem. Pelo contrário, os atos bons podem esconder os maus impactos (greenwashing) e os maus impactos, como são sistémicos, necessitam de uma reorganização do sistema (corresponsabilidade política), não de boas iniciativas dentro do mesmo sistema (filantropia inefetiva). Considerando apenas a problemática da RSU de que serve tomar iniciativas de "campus sustentável" se continua a ensinar, na Faculdade de Economia, economia neoclássica absolutamente cega aos problemas ambientais? De que serve desenvolver projetos de solidariedade com populações indígenas se se continua a negar a possibilidade de uma medicina não ocidental na Faculdade de Medicina? De que serve falar de gestão socialmente responsável da Universidade se não se atacam os preconceitos epistémicos de fundo que conduziram a nossa Modernidade ao estado atual de um desenvolvimento social e ambiental insustentáveis?

\section{0 que deveria ser a RSU?}

Pelo anteriormente exposto, necessitamos de uma teoria da RSU mais racional e coerente do que as atuais práticas de RSO. O mais indicado é mantê-la próxima da definição central de responsabilidade pelos impactos da universidade, recordando que ninguém ode gerir os "seus" impactos sozinho dado que são sociais. A partir daí, a responsabilidade social deve consistir numa dinâmica de associação para a transformação do campo social que reproduz os impactos dos quais participa a universidade. Nesse sentido, o fio condutor de uma definição da responsabilidade social universitária é constituído pelos tipos de impactos universitários e os riscos a eles associados. A especificidade da RSU com relação à responsabilidade social de outras organizações (em particular com a das empresas: a RSE) depende da especificidade dos impactos universitários que dependem, por sua vez, do que fazem as universidades, com quem o fazem, a quem afetam e como podem participar da finalidade de toda a responsabilidade social que é a sustentabilidade social e ambiental da sociedade no seu todo, a nível local e global.

A universidade, ao fazer o que está a fazer, o que é que está realmente a fazer? O quê e a quem é que está a afetar? Como é que participa da atual crise global de insustentabilidade humana no planeta? Como agrava a referida crise ou, pelo contrário, abre perspetivas de solução? Como reproduz ou reduz as desigualdades sociais que recebe em cada ano do seu 
contexto através dos novos estudantes que nela ingressam? Como pode ser agente de mudança social, tecer novas redes no seu contexto, permitir aos atores sociais externos construir novos conhecimentos e novos processos para o desenvolvimento justo e sustentável? Como consegue ser fonte de aprendizagem para todos para lá das suas paredes ou, ao contrário, funciona como claustro universitário fechado? Como se liga ao seu território ou, pelo contrário, se desentende da sua localização e promove um conhecimento e uma formação desligados do seu contexto social? Que atitudes valoriza no seu pessoal docente e não docente, que inspira ou desanima, que processos facilita ou trava?

Cada universidade tem de responder a todas estas perguntas se quer assumir a sua responsabilidade social para além dos discursos sentenciosos e ribombantes que nada mudam nas rotinas institucionais (as declarações de "compromisso social" que não custam nada). Para ajudar os membros de cada comunidade académica na formulação e resposta às perguntas mencionadas, é preciso determinar quais são os tipos de impactos que a universidade provoca no seu labor quotidiano, que tipos de riscos estão associados aos referidos impactos e como promover reflexão e iniciativas a favor de impactos positivos a partir dos mesmos atores universitários (dirigentes, administrativos, investigadores, docentes e estudantes).

Seguindo um duplo eixo organizacional e académico, distingue-se 4 tipos de impactos relevantes na universidade (Figura 1):

1. Impactos internos da própria organização universitária do seu campus para os seus membros e o seu meio ambiente (impactos laborais e ambientais).

2. Impactos externos para a sociedade em geral.

3. Impactos académicos de formação de pessoas.

4. Impactos académicos de construção de conhecimento.

Figura 1 - Impactos relevantes na universidade

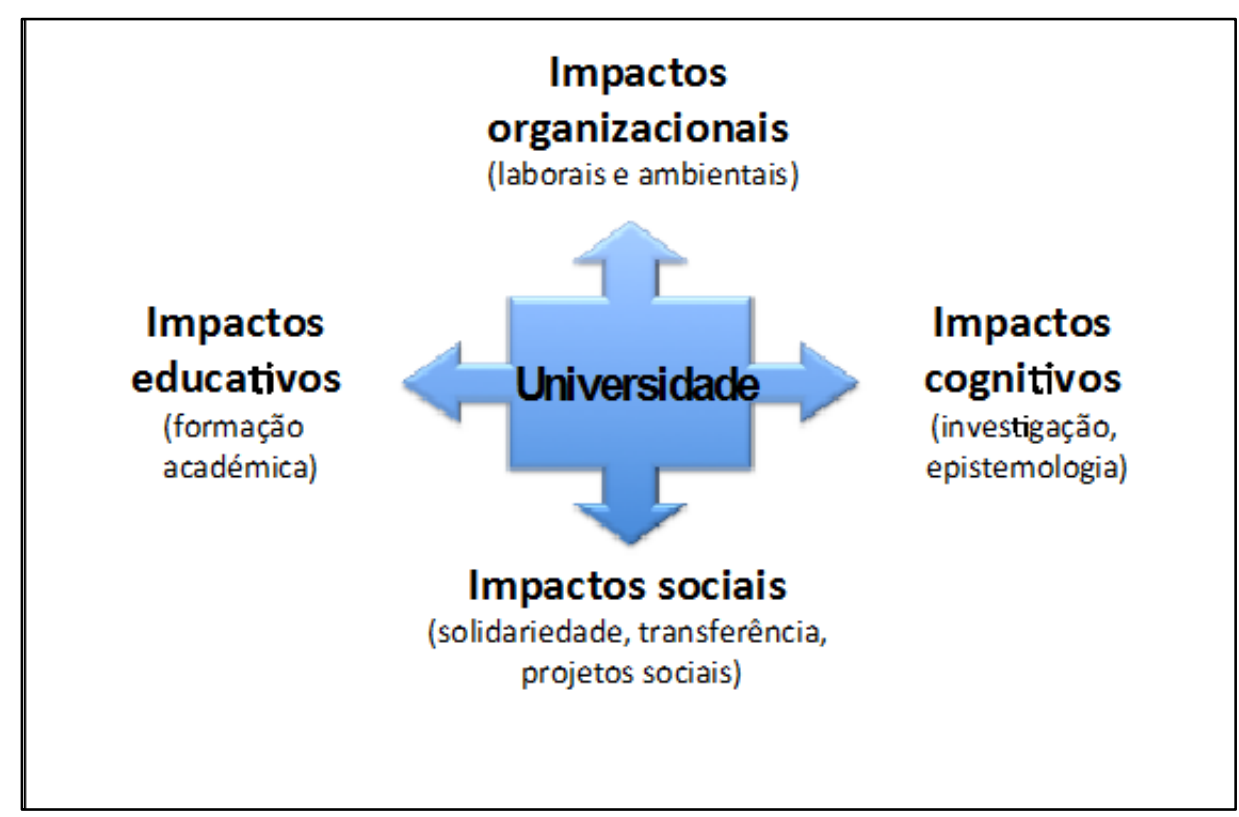

Fonte: Vallaeys (2011). 


\section{Impactos organizacionais}

Como qualquer organização laboral, a universidade impacta na vida dos seus membros (administrativos, docentes e estudantes). Também a forma como organiza as suas atividades quotidianas tem impactos ambientais (resíduos, desflorestação, consumos energéticos dos edifícios, transporte, etc.). Este tipo de impactos desdobra-se, assim, em impactos para as pessoas e para o meio ambiente. A universidade responsável interroga-se sobre a sua pegada social e ambiental: Quais são os valores que vivemos diariamente no campus? Como devemos viver na nossa universidade de forma responsável, com respeito pela natureza e a dignidade e bem-estar dos membros da comunidade universitária?

\section{Impactos educativos}

A universidade influencia a formação dos jovens e profissionais, na sua ética e escala de valores, na sua maneira de interpretar o mundo e de nele se comportar. Incide ainda na deontologia profissional e orienta (de forma consciente ou não) a definição da ética profissional de cada disciplina e o seu papel social. A universidade responsável questiona-se sobre o tipo de profissionais, cidadãos e pessoas que forma, e sobre a adequada organização do ensino para garantir uma formação socialmente responsável dos seus estudantes. Que tipo de profissionais e pessoas estamos a formar? Como devemos estruturar a nossa oferta educativa para formar cidadãos responsáveis pelo desenvolvimento humano sustentável? Serão os nossos diplomados capazes de querer e poder reorientar o rumo de um desenvolvimento global atualmente insustentável e sem equidade, ou apenas procurarão encontrar um emprego?

\section{Impactos cognitivos}

A universidade orienta a produção de conhecimento, influencia na definição do que designa socialmente verdade, ciência, racionalidade, legitimidade, utilidade, ensino, etc. Incentiva (ou não) a fragmentação e separação dos saberes ao delimitar os âmbitos de cada especialidade ou formação. Articula a relação entre tecnociência e sociedade, possibilitando (ou não) o controlo e a apropriação social do conhecimento. Influencia a definição e seleção dos problemas da agenda científica. A universidade responsável questiona-se quanto ao tipo de conhecimentos que produz, quanto à sua pertinência social e quanto aos seus destinatários: Que tipo de conhecimentos produzimos, para quê e para quem? Que tipo de ciência promovemos, uma ciência democrática ou nas mãos da elite? Que conhecimentos devemos produzir e como devemos difundi-los para atender às carências cognitivas que prejudicam o desenvolvimento sustentável?

\section{Impactos sociais}

A universidade tem um peso social enquanto referência e ator que pode (ou não) promover o progresso, criar capital social, vincular os estudantes à realidade exterior, fazer aceder outros atores ao conhecimento, etc. Uma universidade pode fechar-se sobre si mesma 
como um "claustro académico" que partilha um saber desvinculado do ambiente; pode querer apenas imitar o que é feito a nível internacional e não se preocupar com a sua realidade local circundante; ou pode assentar e vincular-se profundamente no seu contexto de forma a participar na resolução de problemas específicos. A universidade responsável interroga-se sobre como pode acompanhar o desenvolvimento da sociedade e ajudar a resolver os seus problemas fundamentais: Que papel assumimos no desenvolvimento da sociedade, com quem e para quê? Como pode a universidade ser, desde a sua fundação e competência específica, um ator participante no progresso social, através do fomento da educação e do conhecimento, para uma responsabilidade social territorial? Com quem nos devemos associar para alcançar esta responsabilidade social territorial?

Os impactos significam riscos, riscos de não cumprir bem com a nossa missão universitária, riscos de sermos incongruentes entre o que declaramos que somos (universitários comprometidos com a sociedade e a excelência) e o que na realidade fazemos, riscos de não perceber, no dia-a-dia, as patologias sociais e ambientais que vamos reproduzindo e fortalecendo. Visibilizar os impactos negativos constitui uma tarefa essencial para que uma organização assuma a sua responsabilidade social. Assim como uma pessoa responsável, uma organização responsável está atenta ao que faz, previne os possíveis futuros adversos, mantém-se em estado de vigília para não se deixar surpreender, toma precauções para diminuir as possibilidades de lamentar alguma coisa.

É totalmente errada a opinião que declara que "a universidade é por si socialmente responsável dado que tem fins educativos e de ciência". A realidade é diferente. Inclusive quando temos finalidades boas e queremos fazer as coisas bem, podemos ter impactos negativos. Do mesmo modo que uma lei pode ser injusta, uma educação pode deseducar e uma ciência pode gerar riscos e ameaças sociais mais do que a solução de problemas humanos. Nenhuma organização está imune aos impactos negativos que gera no seu contexto social e ambiental. E se a universidade forma profissionais e líderes deste mundo social e ambientalmente insustentável quer, sem dúvida, dizer que é corresponsável, desde a sua forma de ensinar e gerar conhecimentos, pelas patologias sociais do seu contexto. Culpada não, corresponsável sim. Podemos produzir um panorama dos possíveis impactos negativos da atividade universitária (Figura 2). 
Figura 2 - Possíveis impactos negativos das universidades

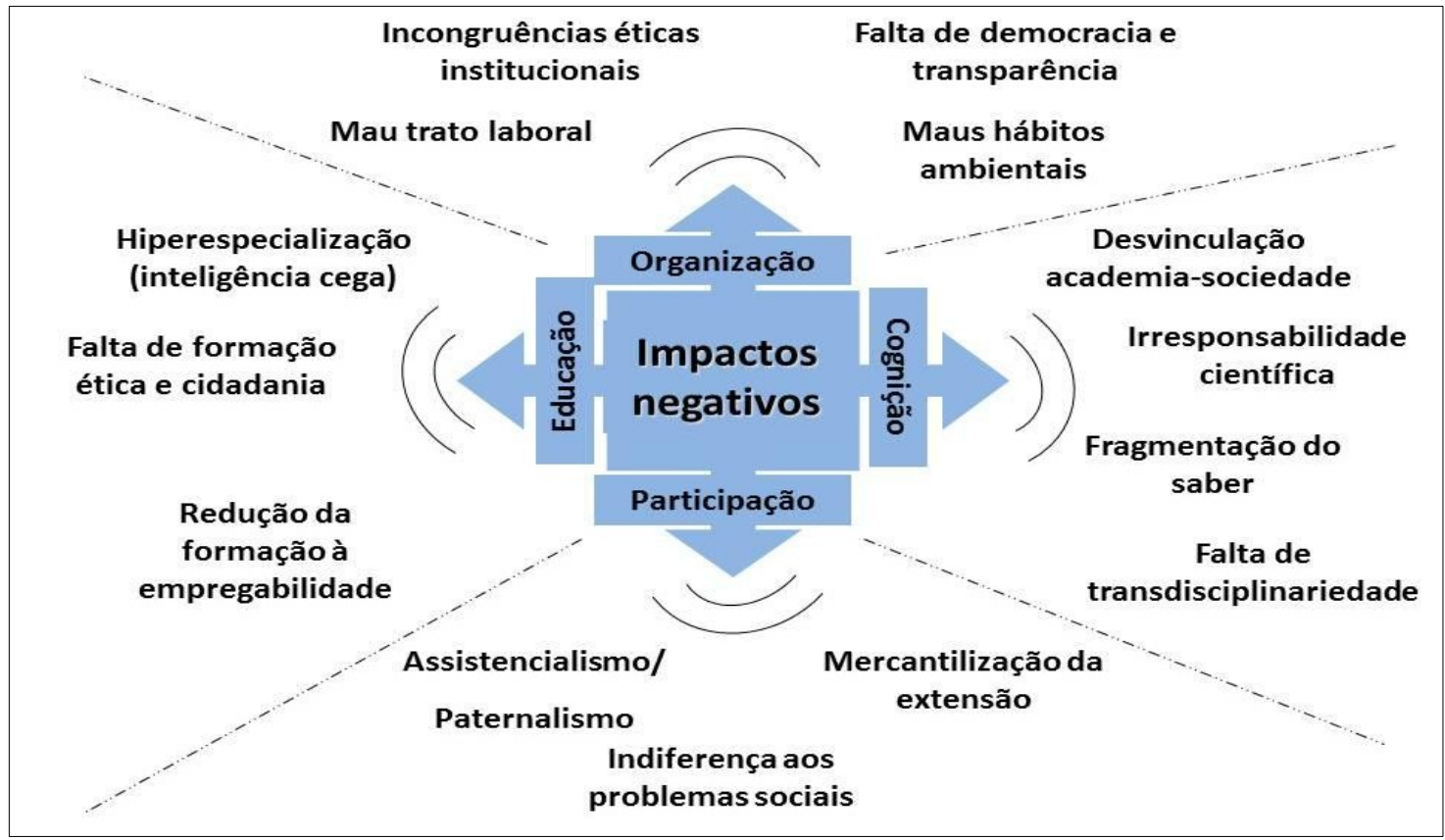

Fonte: Vallaeys (2011).

Os impactos negativos que ameaçam a pertinência e congruência do trabalho universitário são, na realidade, poderosos aiados para nos despertarmos, assombrarmos e motivarmos para fazer coisas novas, criativas, inovadoras, com o objetivo de mudar a vida diária no campus, nas salas de aula, nos laboratórios de investigação e na participação social com agentes externos. Devem servir-nos como bússolas para não cairmos na complacência, inclusive quando devemos estar orgulhosos por cumprir com boas práticas (que as há nas universidades, felizmente!).

Contudo, a luta contra os impactos negativos tem de ser gerida de forma racional. Quatro processos básicos permitem à universidade ser vigiante relativamente aos seus riscos de impactos negativos e incongruências. Trata-se de evitar os quatro perigos de uma organização irresponsável: a corrupção, o autismo, a cegueira e o egocentrismo organizacionais.

1. A boa "governança" (ou bom governo) da universidade: Definir e cumprir de forma congruente com a sua Missão organizacional, implementar um Código de Ética e um Comité autónomo responsável por promover e acompanhar o seu cumprimento, assegurar não apenas o cumprimento das leis nacionais mas também das mais exigentes normas internacionais (laborais, sociais, ambientais), assegurar um bom ambiente de trabalho, lutar contra as discriminações e a iniquidade de género, proteger os direitos humanos das pessoas e relatar, de forma transparente e confiável, os resultados do desempenho organizacional, constituem uma série de recomendações que promovem os instrumentos de gestão da responsabilidade social universitária, basicamente para lutar contra o risco de corrupção da organização.

2. O diálogo com a prestação de contas às partes interessadas: O modelo dos "stakeholders" convida a encarar a universidade como um espaço aberto no qual se 
cruzam interesses e riscos de muitos atores pertencentes (ou não) à comunidade universitária, vinculados (ou não) com ela, afetados pelo seu desempenho e tendo (ou não) poder para a afetar. A universidade deve responder de forma satisfatória às suas "partes interessadas", estabelecer um vínculo e processos de relação transparente e democrática com elas, assim como reportar-lhes, de forma confiável e honesta, os resultados das decisões tomadas. Deve escutar as partes internas interessadas: estudantes, docentes (do quadro e contratados a tempo parcial), investigadores, pessoal administrativo; assim como as externas: diplomados, vizinhos, fornecedores, governos e comunidades locais, Estado, empregadores, ONG, outras universidades. Este processo de regulação socialmente responsável através do diálogo e da escuta luta contra o perigo de autismo da organização.

3. O autodiagnóstico dos impactos meio-ambientais e sociais: A filosofia de gestão da Responsabilidade Social convida a universidade a tornar-se consciente de todas as consequências e efeitos que as suas estratégias de atuação provocam nos domínios humanos, sociais e ambientais. Promovendo o "desenvolvimento sustentável", a universidade deve tomar consciência dos seus próprios impactos na sua envolvente (interna e externa) e resolver os problemas diagnosticados, de tal modo que o funcionamento normal da organização não produza mais os ditos impactos, ou possa mitigá-los de forma a levá-los a níveis legal e socialmente aceitáveis. Sem um autodiagnóstico permanente, realizado pelos mesmos membros da comunidade universitária, pouco podemos fazer para melhorar as coisas e mudar os hábitos adquiridos: o que não se mede dificilmente pode ser melhorado. Desta forma, a responsabilidade social é uma política de gestão que obriga a universidade a examinarse a si mesma e a assumir os riscos dos seus impactos de forma responsável. Para além disso, o autodiagnóstico é fundamental pois constitui uma forma de realizar o bom governo universitário (democracia, transparência) e a audição e prestação de contas a todas as partes interessadas. Ajuda assim a lutar contra o risco de cegueira da organização.

4. As alianças para participar no desenvolvimento social e ambientalmente sustentável do território da universidade: A adequação com a Missão e Valores da universidade, a gestão dos impactos e a participação das partes interessadas, em conjunto, levam de uma lógica reativa a uma lógica proactiva de envolvimento na solução dos problemas sociais da envolvente da universidade, logo à ancoragem social e à criação de redes e alianças para o tratamento conjunto de problemas sociais. A referida estratégia de alianças para a responsabilidade social, não apenas da universidade enquanto tal, mas do território em que opera, será sustentável se a participação externa da universidade retorna a ela sob a forma de melhor formação dos estudantes, melhor gestão do campus, melhor inovação científica e criação de conhecimentos pertinentes. Pelo exposto, a constituição de alianças para o desenvolvimento local não significa gastos de filantropia a fundo perdido. Evitando fazê-la cair na soberba de se considerar a única 
fonte de conhecimentos e pertinência social, a RSU ajuda a universidade a tecer redes com outros atores sociais (governos locais, ONG, empresas, comunidades locais, governo central, organismos internacionais, universidades nacionais e internacionais, etc.) para alcançar metas ambiciosas enquanto transformação social. A RSU ajuda assim a universidade a lutar contra o perigo de egocentrismo da organização.

Este último processo básico de responsabilização social é frequentemente esquecido apesar de, na realidade, ser essencial por uma simples razão: ninguém pode controlar por si só os "seus" impactos, seja para os suprimir ou os mitigar. Isto porque, como vimos, os impactos dos quais participamos como agentes sociais "enredam-nos" literalmente, colocam-nos em redes de inter atores, juntamente com muitos outros atores sociais locais, nacionais e globais. Seria irrealista pensar que uma organização possa resolver por si mesma o "seu" problema de pegada ecológica insustentável, o "seu" problema de participar na reprodução da pobreza dos mais marginalizados pelo sistema económico. Contudo, se a responsabilidade social de qualquer organização é a responsabilidade pelos impactos que provoca na sociedade e no meio ambiente (e esta é a única definição precisa de responsabilidade social) então qualquer vontade de se responsabilizar pelos referidos impactos obriga a associar-se com outros atores sociais para tratar de reorientar processos sistémicos que superam as forças e possibilidades da organização isolada. Assim, toda a responsabilidade social organizacional (RSO) conduz ao dever de associação e criação de alianças para o desenvolvimento justo e sustentável, ou seja, conduz a responsabilidade social territorial (RST) entre parceiros situados num determinado território local, regional, nacional, internacional ou, inclusive, planetário, dependendo do alcance das alianças e dos problemas por tratar.

É inútil considerar a responsabilidade social como um assunto que diz respeito a cada organização de forma isolada, como se se tratasse da sua responsabilidade moral (cumprir com boas ações e recusar atos ilegais e injustos). Ou a responsabilidade social é "social", quer dizer de e entre todos, ou falamos de uma responsabilidade "individual" (pessoal ou de uma organização em particular) e então trata-se de uma simples responsabilidade moral e/ou jurídica.

Os 4 tipos de impactos que definimos permitem, uma vez que entendemos que devemos responder por eles, delimitar quatro âmbitos de gestão socialmente responsável da Universidade (Figura 3). 
Figura 3 - Âmbitos de responsabilização social

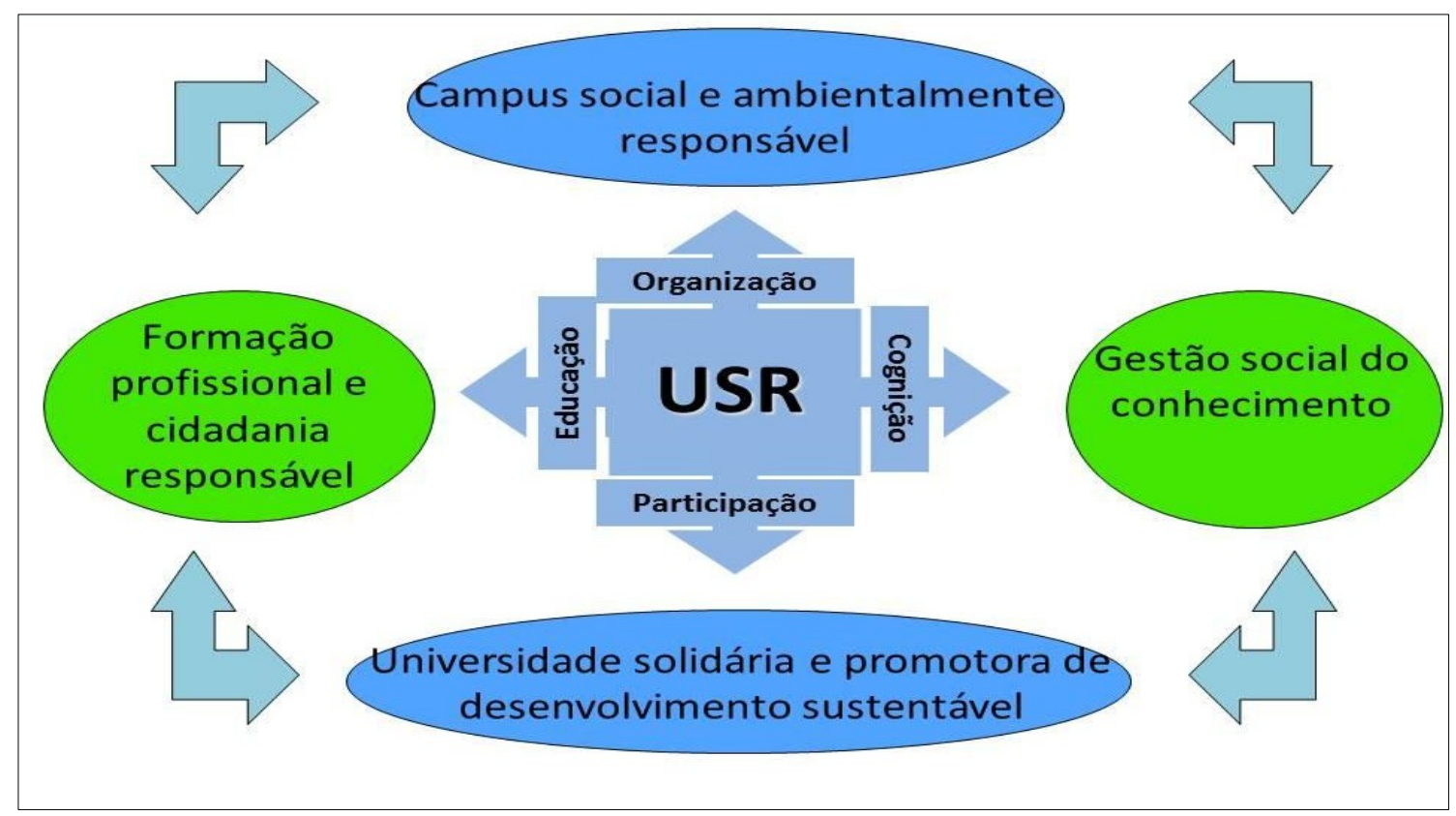

Fonte: Vallaeys (2011)

\section{A RSU como modelo para uma universidade ancorada no seu território, promovendo um conhecimento público e democrático, contra a mercantilização da educação e das ciências}

Nestes tempos de liquefação financeira de toda a economia, tudo tende a tornar-se uma mercadoria de forma a entrar nos fluxos de intercâmbios em redes. O conhecimento não escapa a esta tendência. Duas inovações na fronteira da educação superior apresentam-se atualmente sob um rosto muito simpático, apesar de poderem augurar horizontes sombrios de mercantilização universitária transnacional. O primeiro são os cursos virtuais massivos abertos (MOOC: Massive Open Online Courses), o segundo é o modelo da "Tripla Hélice" (Etzkowitz, Leydesdorff, 1997), que congrega o Estado, as Empresas e as Universidades em torno da inovação da inovação tecno-económica, modelo no qual os poderes públicos e privados se associam para promover uma "ciência empresarial".

Apesar de os cursos virtuais massivos serem, de momento, gratuitos e afirmarem quebrar as paredes do claustro universitário para dar acesso a todos ao melhor conhecimento, o de Stanford, MIT, Harvard (Ver: Coursera, Udacity, EdX) induzem, sem querer querendo, um modelo de conhecimento desgarrado, desancorado, suscetível de ser produzido e difundido para todos, seja qual for a sua história, lugar, idioma, contexto social, tal como qualquer mercadoria adquirida por qualquer cliente. O processo de ensino-aprendizagem ficará assim otimizado como fluxo de informações uniformizadas acessíveis ao maior número possível de clientes igualmente uniformizados. O currículo oculto de dito modelo é a negação do carácter singular e pessoal do processo de ensino-aprendizagem como processo trans-formativo e não apenas in-formativo de uma pessoa. O conhecimento valorizado será aquele que possa ser desligado das suas condições territoriais e intersubjetivas de produção e compreensão. No horizonte está também o desaparecimento da diversidade universitária mundial, o domínio 
exclusivo do inglês (ele mesmo empobrecido em "globish"), o auge do monopólio da educação superior por parte de algumas multinacionais.

O modelo da Tripla Hélice, pela sua parte, tem como currículo oculto (não tão oculto!) a privatização do conhecimento através do pedido público e privado de uma ciência com fins lucrativos. Sem ignorar as vantagens do mercado na promoção de melhorias e inovações para o bem-estar social, é necessário destacar o facto de que o aproveitamento lucrativo de um bem ou serviço necessita que expressamente se proíba o seu livre acesso pelo público, para assegurar que seja vendido e não livremente usado. Se a ciência se torna mercadoria, significa que deve deixar de ser um bem comum e uma atividade democrática aberta, de forma transparente, à crítica pelos pares na comunidade de comunicação (Habermas, 1981; Apel, 1973). O seu uso mercantil (privatizado) contradiz então o seu processo de produção que exige livre exame e crítica universal. Tal é possível apenas se se abandona a procura do saber verdadeiro legitimado pela comunidade aberta dos homens de ciência numa "sociedade aberta" (Popper, 1945) e se pratica uma tecnociência que apenas procura a transformação ativa do mundo, isto é, uma ciência que faz, mas não procura saber. É inútil referir que todos os homens de ciência que procuram saber e, sobretudo, os que alertam para os perigos das inovações científicas (os alertadores: whistleblowers) serão sistematicamente marginalizados pela Tripla Hélice.

Contra tal mercantilização da educação e da ciência, a RSU constrói-se como modelo de universidade ancorada no seu território, ouvindo as suas gentes, preocupada com os seus impactos na sociedade e no meio ambiente local e global, promovendo uma ciência produzida numa comunidade democrática como um bem público não mercantilizável. A RSU convida constantemente à autorreflexão da comunidade académica sobre os seus pressupostos epistémicos e os efeitos da sua ação. É um modelo "ecológico" de academia que trata cada contexto singular de cada universidade, assegura a diversidade académica mundial contra os monopólios e a normalização da produção do conhecimento, dado que acarinha a aprendizagem-ação e a investigação-ação em comunidades de aprendizagem tendo em vista um desenvolvimento justo e sustentável. Nada diz que os seus contributos para o processo cognitivo e espiritual universal da humanidade serão menores do que os do modelo da ciência empresarial e o conhecimento como mercadoria. É tempo de os universitários escolherem para qual dos modelos de sociedade querem trabalhar. Nisto reside a sua responsabilidade moral para com a responsabilidade social.

\section{Referências}

AFL-CIO. Responsibility Outsourced: Social audits, Workplace Certification and twenty years of failure to protect worker rights. 2013. Disponível em: <http://www.aflcio.org/content/download/77061/1902391/CSReport+FINAL.pdf>. Acesso em: 9 set. 2017.

APEL, K-O. Transformation der Philosophie, Frankfurt: Suhrkamp Verlag, 1973.

BECK, U. Risikogesellschaft. Frankfurt: Suhrkamp Verlag, 1986. 
CAPRON, M., Quairel-Lanoizelée F., Turcotte M-F. ISO 26000: une norme "horsnorme"?Vers une conception mondiale de la responsabilité sociétale. Paris: Economica, 2011.

DEWEY, J. The public and its problems. Carbondale: Southern Illinois University Press, 1927, 1984.

ETZKOWITZ, H.; L. Leydesdorff (Éd.). Universities in the Global Economy: ATriple Helix of University-Industry-Government Relations. London: Cassell Academic, 1997.

HABERMAS, J. Theorie des Kommunikativen Handels. Frankfurt: Suhrkamp Verlag, 1981.

JONAS, H. Das Prinzip Verantwortung. Frankfurt: Insel Verlag, 1979.

LUHMANN, N. Macht. Stuttgart: Lucius \& Lucius Verlagsgesellschaft, 1975.

MORIN, E. La Méthode 6: l'éthique. Paris: Seuil, 2004.

OSTROM, E. Governing the Commons. The Evolution of Institutions for Collective Action. Cambridge: University Press, 1990.

POPPER, K. The open society and its enemies. London: Routledge, 1945.

SERRES, M. Le contrat naturel. Paris: François Bourin, 1990.

VALLAEYS, F. Les fondements éthiques de la Responsabilité Sociale. Tese de doutoramento, Universidad de Paris Este, 2011. Disponível em: <http://blog.pucp.edu.pe/eticarsu>. Acesso em: 9 set. 2017.

VALLAEYS, F.; DE LA CRUZ, C. \& SASIA, P. Responsabilidad Social Universitaria,Manual de primeros pasos. 2009. México: McGraw-Hill Interamericana Editores; Bancolnteramericano de Desarrollo. Disponível em:

$<$ http://idbdocs.iadb.org/wsdocs/getdocument.aspx?docnum=35125786>. Acesso em: 9 set. 2017. 